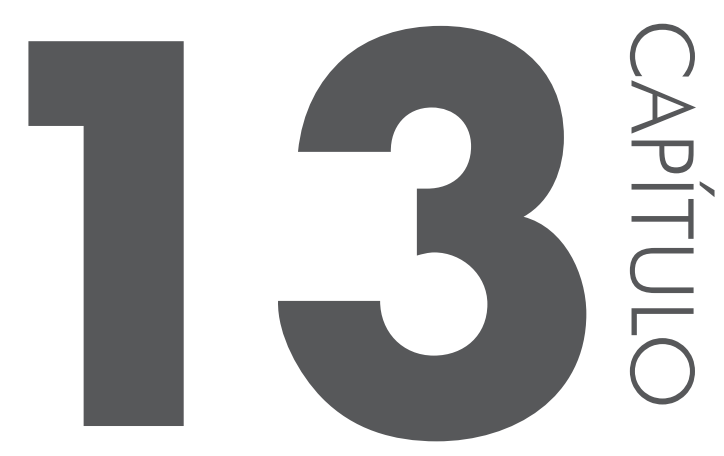

\title{
TECNOLOGIAS DA INFORMAC̣ÃO APLICADAS NA PMSC E BPMA
}

Rosinei Freitas da Rosa

Rangel Machado Simon

Fernando Jose Spanhol

Marcio Vieira de Souza

\section{INTRODUÇÃO}

As dinâmicas colaborativas e em rede são a marca da sociedade da informação e do conhecimento. Em razão disso, é fundamental discutir a utilização das Tecnologias da Informação e Comunicação (TIC) como suporte à Segurança Pública, em especial na proteção do meio ambiente, bem como a otimização do trabalho técnico-profissional dos policiais militares lotados no Batalhão de Polícia Militar Ambiental (BPMA), objetivando a padronização dos conceitos de proteção ao meio ambiente.

A proteção ao meio ambiente é um dos ramos de atuação da Polícia Militar de Santa Catarina (PMSC), que exerce trabalho de preservação da ordem pública e exige, assim, profissionais capacitados para a garantia das liberdades individu- 
ais e coletivas, bem como dos direitos humanos. Mas, além disso, é preciso que esses agentes públicos tenham à disposição aporte tecnológico, para facilitar e melhorar seu desempenho. Assim, o objetivo deste trabalho é expor como é feito esse suporte por meio de TIC.

Nosso ponto de partida está em identificar os sistemas utilizados no âmbito da Segurança Pública, para o desempenho técnico-profissional dos membros da BPMA, para a proteção do meio ambiente.

Para interpretar mais adequadamente os caminhos deste trabalho, partimos da premissa de que, embora a definição de o que pode ser meio ambiente seja elástica, segundo Silva e Figueiredo (1998, p. 139), trata-se aqui somente no que diz respeito ao meio ambiente natural.

Tomamos o conceito de meio ambiente apresentado por Silva (1995, p. 2, apud FIGUEIREDO; SILVA, 1998, p. 140), que o estabelece como "a interação do conjunto de elementos naturais, artificiais e culturais que propiciem o desenvolvimento equilibrado da vida em todas as suas formas". Inclusive esse conceito foi utilizado na Resolução Conama n 306/2002, como se pode ver a seguir:

\section{ANEXO I \\ DEFINIÇÕES}

XII - Meio ambiente: conjunto de condições, leis, influência e interações de ordem física, química, biológica, social, cultural e urbanística, que permite, abriga e rege a vida em todas as suas formas (BRASIL, 2002).

O Caderno Temático de TIC (ABDI, 2010), elenca o fato de as TIC estarem em todas as áreas de atividades, tornando-se o cerne da chamada Sociedade da Informação e, com isso, tem se tornado um segmento econômico valioso aos países desenvolvidos e em desenvolvimento, tomamos para o presente estudo o conceito apresento no mesmo.

Para efeito do presente estudo, Tecnologias de Informação e Comunicação (TIC) correspondem a todas as tecnologias que interferem e perpassam os processos informacionais e comunicativos dos seres. Ainda, podem ser entendidas como um conjunto de recursos tecnológicos integrados entre si, que proporcionam, por meio das funções de hardware, software e telecomunicações, a automação e comunicação dos processos de negócios, dos serviços públicos, da pesquisa científica e de ensino e aprendizagem (ABDI, 2010, p. 16).

A ABDI (2010, p. 38-39), no desenvolvimento do Caderno Temático de TIC, formulou uma questão junto a seus colaboradores quanto aos condicionantes sociais, tecnológicos, econômicos, ambientais, políticos e éticos que mais influenciarão o fu- 
turo do desenvolvimento das aplicações de TIC no Brasil, nos períodos 2008-2010, 2011-2015 e 2016-2025, sendo observado que, dentre este conjunto de condicionantes, é citado "a educação em todos os níveis", que compreende uma formação educacional e tecnológica estruturada, demonstrando assim sua importância.

Quanto ao tema meio ambiente, o Caderno Temático em questão tem, em todas as menções, as aplicações mobilizadoras de maior impacto no Brasil, pois, como se depreende do texto, "vive-se um período no qual a preocupação com o meio ambiente tem sido forte demandador de soluções que o preservem". Visando a esta ação, o mesmo texto apresenta a necessidades de "meios de controles mais eficientes e eficazes, onde sistemas aplicativos permitem à sociedade um maior controle", no caso, o meio ambiente.

Como define a Constituição do Estado de Santa Catarina, em seu capítulo que trata do Meio Ambiente, a Polícia Militar deve possuir uma unidade especial de Polícia Florestal, orientada essencialmente para essa missão.

E desta feita, a atuação da PMSC na área ambiental é exercida por seu setor especializado de proteção ambiental, o Batalhão de Polícia Militar Ambiental (BPMA), que desenvolve atividades de educação ambiental, e quando constatados ilícitos ambientais, promove a lavratura dos procedimentos administrativos e judiciais cabíveis ao caso, sendo essa atuação relacionada à proteção dos interesses difusos e coletivos da sociedade.

Entendemos que a PMSC, como um ramo da Segurança Pública, que "compreende o conjunto de todas as esferas envolvidas na garantia de segurança do cidadão, incluindo a ordem social, a saúde, a integridade da pessoa e a integridade do patrimônio" (ABDI, 2010, p. 56).

Os projetos que envolvem aplicações de Tecnologia da Informação (TI) não requerem dos profissionais de segurança, necessariamente, conhecimentos profundos de informática, contudo, faz-se necessária a difusão de seus conceitos básicos (FURTADO, 2002),

A constante necessidade do aperfeiçoamento do profissional da PMA elevara sobremaneira a qualidade do serviço prestado e, neste caso, como define Furtado (2002, p. 24), "ter um grande impacto no sucesso da empresa, beneficiando-a de diversas formas como: através da melhoria da qualidade dos serviços prestados, redução de erros e consequente redução de custos com maior eficiência das operações”.

A visão da necessidade de aprimorar a qualidade do profissional que executa a atividade de fiscalização do meio ambiente decorre da preocupação com este e suas inter-relações com o desenvolvimento humano e a qualidade de vida, sua evolução ao longo dos tempos, e as instituições que cumprem a garantia de tal preceito constitucional também devem evoluir, acompanhando a inúmeras leis preservacionistas que se adotou no Brasil. 
Partindo desta premissa, temos o presente questionamento: quais TIC podem ser utilizadas para contribuir com a efetivação das atribuições da BPMA?

\section{PROCEDIMENTOS METODOLÓGICOS}

Para tal, foi realizada uma pesquisa descritiva, documental, bibliográfica e um estudo de caso, baseado em dados empíricos do Batalhão de Policia Militar Ambiental (BPMA) do Estado de Santa Catarina.

Sendo a BPMA um órgão que integra o Sistema Nacional do Meio Ambiente, há a necessidade de se buscar novas tecnologias para alavancar a capacidade produtiva do efetivo dessa unidade de proteção ao meio ambiente.

Este autor, Rosinei Freitas da Rosa, faz parte do efetivo do $2^{\circ}$ Pelotão da $3^{\text {a }}$ Companhia do Batalhão de Polícia Militar Ambiental, que possui um número reduzido de policiais (17) e cujo efetivo tem o compromisso de efetuar o policiamento de prevenção e fiscalização das atividades nocivas ao meio ambiente, nos 24 municípios que compreendem a Associação dos Municípios da Região Carbonífera (AMREC) e a Associação dos Municípios do Extremo Sul Catarinense (AMESC), sendo que tal dificuldade de efetivo se reproduz nas demais unidades da BPMA.

Ao se identificar e buscar orientar a necessidade de desenvolver novas tecnologias que possam auxiliar nas atividades do policiamento ambiental, poderemos assim ampliar e melhorar a capacidade de trabalho de todos.

Para o desenvolvimento deste trabalho, focou-se na atividade de proteção do meio ambiente por meio da BPMA, sendo que dentro do Caderno Temático de TIC (ABDI, 2010, p. 22), para a construção da visão de futuro, foram selecionadas sete aplicações considerando os objetivos dos cinco subprogramas do Programa Mobilizador em TIC da Política de Desenvolvimento Produtivo: (iii) sistemas aplicados à segurança pública: (v). sistemas aplicados à energia e ao meio ambiente.

Ao associarmos segurança pública e meio ambiente, em Santa Catarina temos, na PMSC, por meio da BPMA, a devida conjugação destes temas e, portanto, a necessidade de sua integralização e aperfeiçoamento.

\section{TIC UTILIZADAS PELA PMSC}

Antes de descrevermos as TIC utilizadas pela PMSC, faz-se necessário uma visita ao Plano Estratégico da PMSC 2005-2020 (SC, 2005) e ao Plano de Comando apresentado em 2011(SC, 2011).

Em junho de 2005, por meio da Portaria n ${ }^{\circ}$ 020/PMSC, de 11 de janeiro de 2006, foi aprovado o Plano Estratégico, do então comandante geral Bruno Knihs, que tinha o objetivo, segundo suas próprias palavras, de "manter a instituição 
viva dentro do período em que se passa de grandes transformações no âmbito econômico-social, tecnológico e política” (SC, 2005).

Nesse Plano Estratégico, foram apresentadas algumas diretrizes, em que se definiu a importância na prática interna da instituição, traçando assim suas estratégicas quanto a sua função pública e que tal planejamento é um processo contínuo e permanente, que considera os pontos fortes e fracos da organização.

Para o desenvolvimento deste trabalho, a Diretriz $n^{\circ} 8$ (SC, 2005) mostra-se a mais adequada, pois trata do uso das tecnologias, prevendo, entre suas ações, a promoção da inovação e da modernização tecnológica da Polícia Militar, bem como se propõe a mapear os sistemas de informação existentes; projetar a integração desses sistemas, implantando banco de dados adequado à arquitetura Data Ware House; desenvolver novos sistemas de informação; e desenvolver o novo aplicativo de registro de atendimento e despacho de ações policiais (emergência 190).

Entendemos que foi um avanço o Plano Estratégico para a PMSC, pois se tem um arcabouço de ações e de definições para realizar sua missão. Segundo Senasp (2009, p. 2):

[...] para que no enfrentamento diário contra os sinistros e desastres, contra a violência e o crime, haja resultados positivos, há que estar atento a essas mudanças. Para atender com excelência à sociedade, o cliente, é preciso entender a razão da existência das corporações, saber claramente como realizar as missões e, vital, posicionar-se quanto ao futuro.

Segundo a divisão contida dentro da estrutura da PMSC, esta possui órgãos de direção, de apoio e de execução. Aos órgãos de direção, cabe o processo de gestão da instituição, objetivando a implantação das políticas necessárias para a realização de sua função no âmbito da segurança pública; aos órgãos de apoio fica o encargo das atividades nas áreas de Logística, Finanças, Instrução, Ensino, Saúde, Promoção Social, entre outros.

O Plano de Comando assim menciona quanto às Tecnologias da Informação e Comunicação:

\subsubsection{TECNOLOGIAS DA INFORMAÇÃO E COMUNICAÇÃO}

2.2.8.1 Sistemas informatizados de gestão operacional

2.2.8.1.1 Sistema de Atendimento e Despacho de Emergências

Implantar nas Centrais Regionais de Emergência (CRE) e Centrais de Operações Policiais Militares (Copom) o Sistema de Atendimento e Despacho de Emergências (Sade).

2.2.8.1.2 Sistema de BI (Business Intelligence) 
Disseminar na corporação a utilização do BI (Business Intelligence) como suporte ao processo de tomada de decisão.

\subsubsection{Inteligência embarcada}

Ampliar a instalação de computadores ou tablets em viaturas, no sentido de ofertar informações qualificadas em tempo real e o registro dos atendimentos realizados.

2.2.8.3 Radiocomunicação (SC, 2013).

\section{CONSIDERAC̣ÕES FINAIS}

A PMSC, em decorrência de uma nova visão estratégica, tem buscado dispor de TIC como forma de melhorar suas atividades e assim prestar um melhor serviço ao cidadão, em especial no tocante ao meio ambiente, de modo que essas tecnologias passem a ser vistas como investimentos essenciais à gestão e não mais como despesa superficial, a ser incorporada ao plano plurianual da instituição.

A concepção em que devemos nos adaptar para assim termos uma reformulação de nossos pensamentos também ocorre com nossas instituições, em que estas devem ter como base a constante necessidade de mudar seus paradigmas e acompanhar esse turbilhão de mudanças que a globalização propicia e a velocidade com que ela chega, caracterizando o estado de necessidade de sobrevivência.

A PM como um todo tem a função de prestador de serviço à comunidade, sendo este serviço prestado de forma ininterrupta, 24 horas por dia. Seu desafio é acompanhar as constantes mudanças sociais e as exigências que se tem da criação de instrumentos que garantam sua finalidade para ter mais eficiência e eficácia em suas ações.

A base conceitual sobre o tema foram as TIC usadas pela PMSC, em particular aquelas que aderentes ao trabalho da BPMA. Devido a um dos autores ser membro do $2^{\circ}$ Pelotão da $3^{a}$ Companhia do Batalhão de Polícia Militar Ambiental, tomamos por base as atividades exercidas neste local que, por ser uma unidade da BPMA, reproduz sua estrutura em nível de Estado.

Dentro de uma perspectiva, verifica-se que as TIC se tornaram uma força motriz dentro da PMSC, e este novo paradigma de transformação e desenvolvimento pode ser um novo modelo a se implantar, visando mudar as formas de interação da sociedade com a instituição, pois a excelência na execução de sua função pode elevar sobremaneira seu valor para a sociedade. Exemplo disto é o BO Online, documento que o cidadão pode retirar de qualquer lugar do Brasil pertinente a seu atendimento.

Entretanto, deve-se ampliar a ação de transformação, atingindo maior nível de interação com as TIC, fazendo com que as informações dispostas dentro da estrutura tornem-se conhecimento agregador. 
Pode-se evidenciar que a PMSC levou algum tempo e ainda apresenta certa dificuldade para vislumbrar as possibilidades das TIC e suas vantagens de aplicação, embora este quadro possa vir a mudar gradativamente, como os últimos cinco anos demonstram.

Há diversos tipos de sistemas que foram desenvolvidos para atender as diversas atividades funcionais da PMSC, tanto corporativos, como estratégicos e específicos. Contudo, a adoção do SISP (antes, Sistema de Informática do Serviço Público, depois Sistema de Administração dos Recursos de Tecnologia da Informação), após este passar a ser administrado pela SSP, é uma ação que à época indicou um futuro a ser seguido, resultando no sistema SADE, criando assim um ambiente de futuro, em que, desta forma, criasse uma estrutura coordenada para a ação conjunta dos órgãos de segurança.

Silva et al. (2008), em seu artigo que trata da aplicabilidade do SISP, demonstra claramente a necessidade da integração dos sistemas públicos de segurança, fato que levou algum tempo a ocorrer.

Pode-se dizer que, em razão de certas dificuldades de se fazerem comunicar as estruturas de segurança, surgiu o conceito de que se faz necessária a integração dos sistemas de segurança. Cabe à SSP colocar um norte neste caminho e exercer seu poder de decisão para que ocorra tal fato.

É necessário que exista uma estrutura única de Segurança Pública. Se isso não ocorre fisicamente, que ocorra dentro da necessidade na integração das TIC, dos órgãos de segurança, fazendo com que se tenha mais conhecimento quanto aos fatos delituosos ocorridos, o que ajudará cada vez mais na tarefa de suplantá-los e buscar sua redução.

Estas concepções visam desburocratizar boa parte dos processos, gerando ganhos às instituições de segurança e, por conseguinte, para sociedade.

Devido à análise feita durante esta pesquisa, consegue-se chegar ao um resultado previamente estabelecido de que o problema da pesquisa era verificar quais ferramentas de TIC poderiam auxiliar na ação de policiamento da BPMA. Foi constatado que a BPMA não possui sistema garantidor de suas informações, pois não se encontra informatizado e, consequentemente, estão parametrizados, fazendo com que o planejamento estratégico seja executado com dificuldade.

A BPMA não dispõe de seus dados de modo informatizado e acessível via sistemas, nem de banco de dados centralizado, como os utilizados pela PMSC, no registro de ocorrências. Tendo esta possibilidade, ocorreria uma economia de recursos físicos e humanos, além de facilitar a busca por informações e dados, que seriam automatizados, bem como o armazenamento e a confiabilidade na geração de relatórios e análise estatísticas seriam melhores.

Os objetivos foram atingidos, pois foi possível verificar os sistemas existentes na PMSC que podem ser usados na BPMA para auxiliar sua atividade e, assim, otimizar os serviços realizados. 
As possíveis ações para minimizar os efeitos gerados pelas ocorrências de danos ambientais são muitas, e pode-se dizer que, com a intensificação no uso das TIC, esta tarefa seria mais bem realizada.

Temos a percepção que o avanço tecnológico leva a grandes transformações nos campo econômico, social e político, e, para tanto, a BPMA tem que se especializar, alicerçada em um uso mais intensivo das TIC. Deve-se incorporar em sua estrutura eficientes sistemas de informações, pois os trabalhos pertinentes à proteção da natureza não podem estar desassociado das constantes mudanças e renovações pelas quais passam a sociedade e as instituições.

A utilização de informações nas áreas governamentais para subsidiar as tomadas de decisões pelos agentes públicos configura uma forte arma para combater a má utilização da máquina pública. É sabido que essas informações devem ser geradas de forma correta, confiável e com precisão, pois, do contrário, podem inviabilizar a sustentação necessária para estratégias fundamentais para a gestão.

As considerações finais deste trabalho estão estruturadas de acordo com os objetivos específicos localizados no primeiro capítulo:

a) Desenvolver uma pesquisa bibliográfica sobre o uso de TICs na BPMA. Dentro do levantamento feito, constitui-se uma única ferramenta de TIC, o GAIA, ferramenta usada na estrutura da BPMA para gerenciar as multas aplicadas por delitos ambientais em Santa Catarina. Essa ferramenta é gerida pela Fatma, com suporte do Centro de Informática e Automação do Estado de Santa Catarina (Ciasc) e compartilhada com a BPMA. Outras TIC utilizadas pela BPMA são aquelas empregadas na área administrativa, decorrente dos setores de Recursos Humanos, Patrimônio e Financeiro, que valem para toda a PMSC, sendo necessária a elaboração de uma plataforma de TIC para o registro de ocorrências ambientais como determina o Tribunal de Contas do Estado (TCE), em sua auditoria quanto às multas ambientais aplicadas.

b) Identificar e descrever a natureza das TIC, presentes na PMSC, para policiamento ambiental.

Esta pesquisa identificou e descreveu as TIC presentes na PMSC, sendo constatado que a única TIC, usual do setor de policiamento da PMSC e aplicada na BPMA, é o CHIPSAT, usado para rastreamento da frota, em que este pode apresentar um roteiro do local da ocorrência e gerar um mapa para, nesse local, retornar em data futura e efetuar uma vistoria quanto à situação do mesmo, muito válido para situações de ocorrências em locais de difícil localização.

c) Apresentar quais TIC que podem ser aderentes à função BPMA. Durante a pesquisa, observou-se que todas as TIC de cunho administrativo são utilizadas pela BPMA. Contudo, a parte operacional tem sérias 
dificuldades e o sistema SADE e SISP seriam de grande valia para a estrutura, bem como a nova TIC de Mobile SISP pode ser um grande ganho, desde que devidamente estruturada para a finalidade de fiscalização ambiental e produção de relatório.

Não tendo este trabalho o objetivo de esgotar a discussão sobre as TIC existentes na PMSC e que podem ser aderentes a BPMA, entendemos ser necessário um aprofundamento em trabalhos futuros quanto à falta de TIC que efetuem o controle de ocorrências ambientais dentro da BPMA, uma possibilidade de adequação de uma janela de uso para a BPMA dentro do SISP e de possíveis ganhos quanto à gestão do trabalho desenvolvido pela BPMA, com o auxílio de TIC para o desenvolvimento de um planejamento estratégico com vista à redução de determinados delitos ambientais.

\section{REFERÊNCIAS}

AGÊNCIA BRASILEIRA DE DESENVOLVIMENTO INDUSTRIAL - ABDI. Sistemas Aplicados à Segurança Pública. Brasília: ABDI, 2010. 226 p. (Cadernos temáticos TICs - IBDI, 3).

. Ministério do Meio Ambiente. Conselho Nacional de Meio Ambiente (CONAMA). Resolução Conama n 302, de 5 de julho de 2002. Brasília, 2002. Disponível em: <http://www.mma.gov.br/port/conama/res/res02/res30602.html>. Acesso em: 28 abr. 2016.

. Resolução Conama no ${ }^{\text {306, de }} 5$ de julho de 2002. Estabelece os requisitos mínimos e o termo de referência para realização de auditorias ambientais. Brasília, 2002. Disponível em: <http://www.mma.gov.br/port/conama/legiabre.cfm?codlegi=306>. Acesso em: 30 mar. 2016.

FIGUEIREDO, G. J. P.; SILVA, S. T. Elementos balizadores da ação estatal na defesa dos bens ambientais para as presentes e futuras gerações. Temas de Direito Ambiental e Urbanístico. São Paulo: Max Limonad, 1998, ano II, n. 3, p. 136-153.

FURTADO, V. Tecnologia e gestão da informação na segurança pública. Rio de Janeiro: Garamond, 2002.

SANTA CATARINA - SC. Plano de Comando da Polícia Militar de Santa Catarina de 2011. Florianópolis: PMSC, 2011.

Plano Estratégico 2005-2020. Florianópolis: PMSC, 2005.

SILVA, E. R. G.; OLIVEIRA, T. P. S.; BEDIN S. P. M.; ROVER, A. J.; KERN, V. M. Visão sistêmica na interoperabilidade dos sistemas para segurança pública estudo do caso de Santa Catarina. Anais da Conferência Ibero-Americana WWW/internet. Lisboa: IADIS Press, 2008, p. 377-384. 
